\title{
Remembering Prakash Sarvotham Shetty MD, PhD, FRCP [1943-2018]
}

\author{
A. V. Kurpad ${ }^{1}$ - M. J. Müller² R. C. Weisell ${ }^{3}$ M. J. Soares $\mathbb{C}^{4}$
}

Received: 4 October 2018 / Accepted: 4 October 2018 / Published online: 22 October 2018

(c) Springer Nature Limited 2018

Prakash Shetty passed away on 3rd September 2018, leaving a sad void for his many students, friends and admirers. He started his professional life in Christian Medical College (CMC) Vellore, India where he completed his undergraduate and postgraduate education. His classmate, Abraham Joseph reflected; "Prakash was one of the outstanding students of our class, he was the recipient of several prizes throughout his student career, and was greatly respected by his classmates. He had an inquisitive mind and at times his questions would embarrass the teacher who had no answer. This quest for knowledge was not just to pass examinations with distinction, but to really understand the functioning of the human body". His teacher, P Zachariah wrote; "I was delighted when Prakash sought to specialise in Physiology by joining the then fledgling MD program. He got his MD in 1972, and in doing so, gave a flying start to the postgraduate program in Physiology at CMC. Even at that point his keenness to teach, and teach very effectively, was obvious". He was much admired by his students there. Shiv Pillai, his former student, recounts "we first connected with Prakash Shetty when we were second year medical students and he was a young faculty member in the Physiology department. He was an inspirational and accessible mentor, whose passion for science, for biomedical research and for life in general,

$\triangle$ A. V. Kurpad

a.kurpad@sjri.res.in

1 Department of Physiology, St. John's Medical College, Bangalore 560034, India

2 Institute of Human Nutrition and Food Sciences, Christian Albrechts Universität, Kiel, Germany

3 Former Nutrition Officer in the Nutrition Planning, Assessment and Evaluation Service, Food and Nutrition Division, FAO, Rome, Italy

4 School of Public Health, Curtin University, Bentley Campus, Perth, Western Australia, Australia was infectious. Apart from a deep intellectual interest in all things scientific, Prakash was a renaissance man-very knowledgeable about culture, literature, classical music, history and food".

After he moved to St. Johns Medical College in Bangalore, students there also remembered their first electric experiences with him as their lecturer in Physiology. An exceptionally gifted teacher, he communicated his passion for the subject with a style that almost seemed extempore, and his students hung on to his every word. It was St John's however that his work on nutrition began to take shape. He was critical of the belief at the time, that energy requirements were astonishingly low in developing countries, and that adults in these countries appeared able to undertake feats of physical endurance on much lower energy intakes than would be expected [1]. His initial studies on energy intake in undernourished adults at St John's led Prakash to the Dunn Clinical Nutrition Centre in Cambridge, on a Nehru Scholarship from the Indian Government. There he pursued a $\mathrm{PhD}$ on human thermogenesis with Philip James, who remained a valued friend and collaborator over the years, and even supervised Prakash's students in their postdoctoral fellowships. That was a time of great interest in energy expenditure, and whether a possible defect (or an adaptation) in energy expenditure resulted in obesity. Many colleagues embraced the idea which was mainly based on data obtained in obese animals. Roland Jung, Prakash Shetty and Philip James were one of the first authors providing human evidence for this idea [2]; a landmark paper. In addition they went beyond those observations to try and explain that adaptation as a specific action of catecholamines'. This was another landmark paper by the group [3]. Besides other scientific interests, Prakash retained this line of investigation for many years. In 1999, he (together with other leading scientists of that time) had published an outstanding review on metabolic adaptation to low energy intakes [4]. This work was also part of a Report of the International Dietary Energy Consultative Group Working Group (IDECG) [5]. 
Fig. 1 Prakash with some of his $\mathrm{MD}$ and $\mathrm{PhD}$ students, circa 1986. This picture was taken on the roof of St John's Medical College, Bangalore. Left to right: S Piers, A Kurpad, P Shetty, R Kulkarni, M Soares, M Vaz

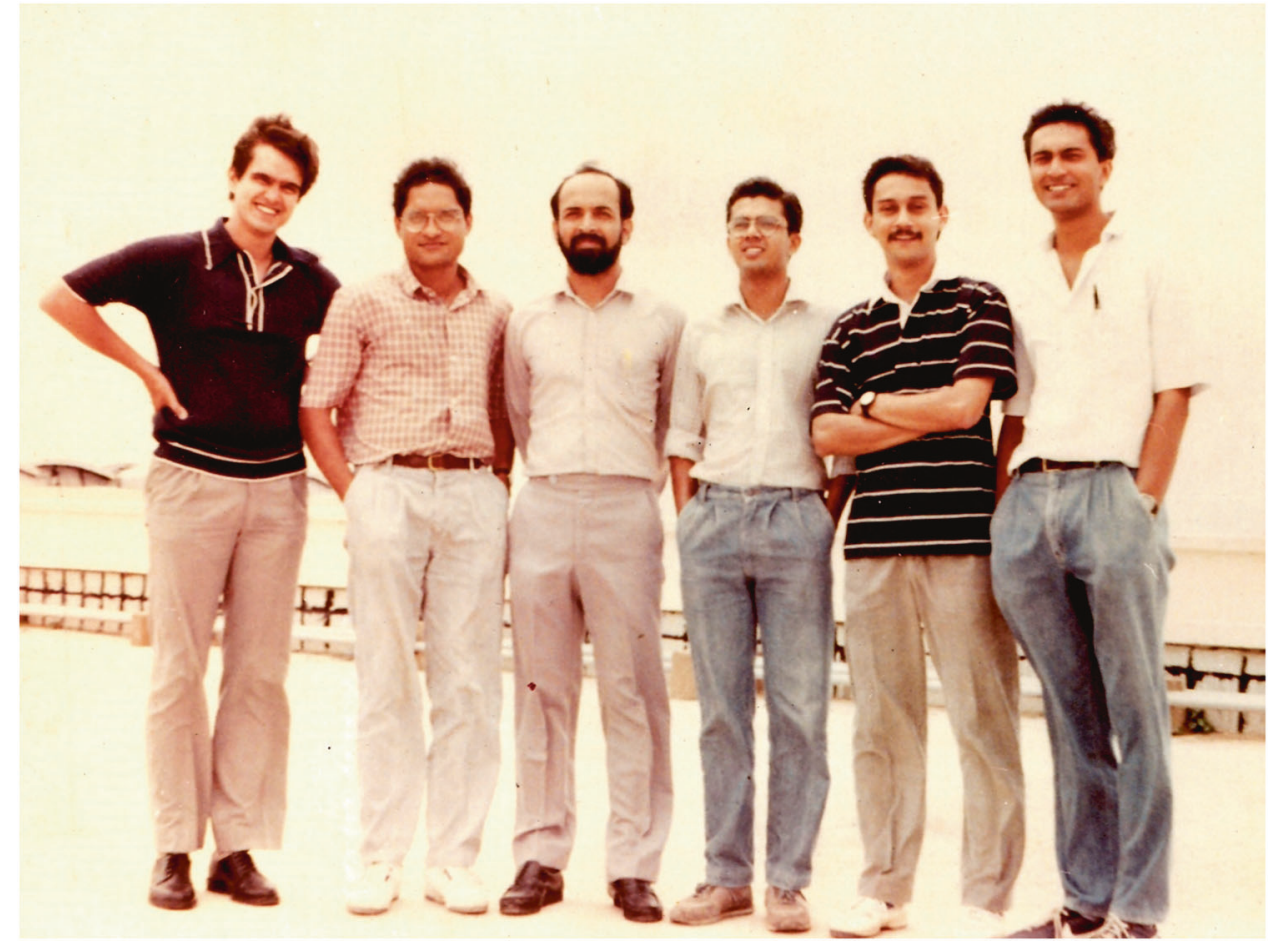

He returned from Cambridge to take over as the Head of Physiology at St John's and began the process of refashioning the department to include nutrition and metabolism as a major research focus. This was sometimes seen as outrageous to the medical physiology traditionalists, and progress was slow. What was remarkable however was that he could, with no equipment or funds at the time, attract many young medical and nutrition graduates to his laboratory. This stemmed from the gift of strong leadership. He shared his dreams openly, and as the 'boss' never hesitated to show his own weaknesses too; a facet that made everyone reflect on their own failings but endeared him to all his students. Many of them have gone on to make a career in Nutrition and Physiology, and others have branched into other fields of research. Even so, all his former students would keep in touch, and would unfailingly visit him at the labs, which had become their intellectual home. That was the point: it was not the office or the alma mater that they came back to; they came for his intellectual stimulation and friendship. (Fig. 1)

At Cambridge, Prakash worked with a whole body indirect calorimeter, and on his return he built an animal calorimeter [6] with DV Muralidhara his PhD student; a human whole body indirect calorimeter followed through a Wellcome Trust grant [7]. Peter Murgatroyd from the Dunn in Cambridge came to help in a heroic way; battling the heat, illness and lack of air conditioning. So began Prakash's many investigations into total energy expenditure and its components in chronically undernourished adults.
He continued his work with Philip James, with an important monograph on chronic energy deficiency and the body mass index (BMI) [8]. He also expanded his investigations in chronic undernutrition to work with isotopic methods to investigate metabolic changes in undernutrition; this led to the establishment of a stable isotope laboratory through a large grant by the Department of Science and Technology.

He collaborated with many scientists from around the world. When they visited Bangalore, they invariably stayed at his home, where his wife, Nandini, and he were gracious hosts. They built a global family and we were privileged to be part of it. John Waterlow visited him often in those days, and would spend time with every student, listening to their research findings and posing difficult questions. On one occasion he spotted a metabolator [used for teaching purposes], that could accurately measure oxygen consumption and carbon dioxide production and hence metabolic rate. $\mathrm{He}$ urged Prakash to begin using this instrument to evaluate adaptations in the BMR to chronic undernutrition. The work on the BMR and chronic undernutrition led to a series of papers by him with his student (one of the authors, MJS) that laid to rest the autocorrelation hypothesis of the adaptation of the metabolic rate to energy intake. At the same time, John Waterlow got Prakash to begin investigations into protein turnover in chronic undernutrition using ${ }^{15} \mathrm{~N}$ glycine and the end-product method [9]. Alan Jackson was central to that thinking and isotopic analysis, where a difference between visceral and muscle protein turnover in chronically undernourished Indian men was proposed. Then 
there was Anna Ferro-Luzzi, Geraldine McNeil, Philip James, Jo Hautvast, Mauro Valencia, to name a few. Particularly with John Waterlow, Prakash would hold court in the evenings at his house, with all his research students present. A bottle of Old Monk rum (Waterlow's favourite) would magically appear and the evening's proceedings were much enlivened. In later years many of Jo's students would spend a year of their MSc placement at St Johns and this led to collaborative papers and life-long friendships with many of them.

It helped that in all these dialogues and social occasions, Prakash was open to many non-scientific issues. In fact he loved to discuss history, culture and Hindu temples. He was very interested in the history of medicine, and wrote a critical appraisal of Avicenna and his contribution to physiology [10]. Shiv Pillai reminisces,..."one could learn from Prakash about the intricacies of brown adipose tissue and fat metabolism, discuss circadian rhythms and the biology of bats or perhaps receive an exposition on medicine in ancient India based on his remarkable photographic records of temple sculptures and murals. The latter were obtained from remote villages and hamlets across the country, all depicting disease and medicine as conceptualised by artists and artisans across the centuries".

Prakash left St John's in 1993, to take up the Chair in Human Nutrition at The London School of Hygiene and Tropical Medicine (LSHTM). In 2001, having completed eight successful years as Professor and Head of Public Health Nutrition at LSHTM, Prakash joined the FAO as Service Chief of the Nutrition Planning, Assessment and Evaluation Service, Food and Nutrition Division. However, Prakash's association with FAO (and at times jointly with WHO) covered a span of approximately 25 years, beginning in the early 1980's. The substantive association with Prakash began as a result of the report of the 1981 Joint FAO/ WHO/UNU Expert Consultation on Energy and Protein Requirements. Several issues arose for which further investigation was required in order to apply accurately the proposed methodology for determining requirement levels. Two such issues, relevant to his work at St. John's in Bangalore, were in relation to the question of whether the BMR of Indians was truly 10\% lower than those of Europeans of similar weight as suggested from the analysis of the BMR data drawn from the literature; and what activity regimen would expend, over 24-h, an energy amount equivalent to roughly 1.3 times the BMR.

Since Prakash had recently constructed (using local materials and technical expertise) and installed an indirect calorimeter at St. Johns, FAO issued several contracts to address the two issues listed above, in addition to others. This productive association continued over a number of years during Prakash's tenure at St. Johns and after his departure. In 1986, the United Nations University (UNU) and the International Union of Nutritional Sciences (IUNS) founded the International Dietary Energy Consultancy Group (IDECG) with five objectives related to research on dietary energy. The Nestlé Foundation agreed to serve as the secretariat of IDECG with UNU, WHO and FAO supporting this activity. A series of research studies commenced over the next 20 years and Prakash was intimately involved as a researcher and advisor. The results of IDECG studies and meetings were reported in a number of publications, many through the European Journal of Clinical Nutrition (EJCN).

$\mathrm{He}$ initiated a number of invaluable activities at FAO. Most notable were the 2001 Joint FAO/WHO/UNU Expert Consultation on Human Energy Requirements (a revisit to the 1981 Expert Consultation mentioned previously) and the 2002 Joint WHO/FAO/UNU Expert Consultation on Protein and Amino Acid Requirements in Human Nutrition (again a revisit to the 1981 Expert Consultation). However, most noteworthy and ambitious, was his directing FAO in concert with WHO towards addressing the issue of obesity and chronic diseases and their link to diet and nutrition, particularly in the developing world. While WHO had examined the subject of Diet, Nutrition, and the Prevention of Chronic Diseases in 1989, FAO had consistently seen its mandate confined to undernutrition, and substantial resistance existed within FAO to broadening its mandate. However, Prakash was instrumental in widening the definition and problem of malnutrition and instructing the FAO hierarchy on the concept of the double burden of noncommunicable diseases. This initiative resulted in a Joint WHO/FAO Expert Consultation on diet, Nutrition and the Prevention of Chronic Diseases in 2002. His departure from FAO in 2005 did not end his involvement with FAO's work and mandate. In the subsequent years he continued to advise FAO and worked primarily with the its Global Perspective Studies Unit, contributing to major FAO publications such as The State of Food Insecurity in the World, which was updated each year and World agriculture: towards 2030/ 2050: Interim report; prospects for food, nutrition, agriculture and major commodity groups. He continued to emphasise the detrimental impact of obesity and noncommunicable diseases in the developing world in publications, primarily with Josef Schmidhuber of FAO's Global Perspective Studies Unit [11, 12].

In November 2002, Manfred Muller invited Prakash to co-Chair a session on public health nutrition as part of the European Public Health Association (EUPHA) conference in Dresden, Germany. At this time Prakash was working for the FAO in Rome, and he gave a wonderful lecture on that occasion on 'Addressing the limits of energy requirements: implications for lifestyle changes'. It was impressive for bringing together data on energy expenditure from different regions of the world and for expanding the classical 


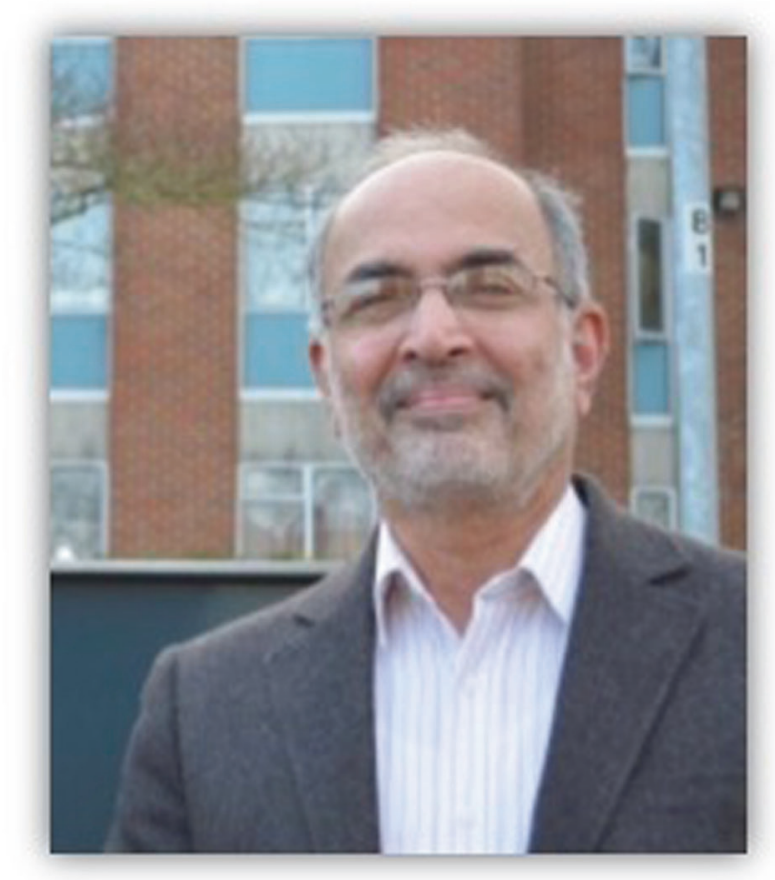

Fig. 2 In his Southampton and LANSA days, circa 2015, UK

concepts of energy physiology to chronic malnutrition and population health. Thus, starting from physiology, he was able to address one of the most challenging public health issues, i.e., chronic malnutrition. Prakash also recognised the value of social determinants of health and nutrition, and often quoted from Marmot \& Wilkinson's impressive text on the subject.

After his stint at FAO, Prakash took up an appointment at Southampton University as Professor of Public Health and began his tenure as Editor in Chief (EiC) of EJCN in 2007. He was always full of ideas and hopes for the journal [13], but found some of his efforts stymied by the huge backlog of manuscripts he inherited and certain administrative imperatives. Nevertheless during his tenure, the EJCN experienced a remarkable growth and standing, rising from an impact factor of 2.163 to a peak of 3.072. During this period his close discussions with Manfred continued, and in 2011 he invited Manfred to take over his EiC position. At this point Prakash was experiencing the first of several health issues that were to follow. However, it did not stop him from continuing his affiliation with EJCN and taking on a challenging new role as CEO of the LANSA (Leveraging Agriculture for Nutrition in South Asia) consortium [http:// lansasouthasia.org/content/prakash-shetty]. In fact, despite his poor health in 2018 , he found the time to communicate his thoughts in that field to the 30th Anniversary issue of EJCN, published this September [14]. (Fig. 2)
Prakash Shetty was an outstanding scientist and much loved individual. He never viewed nutrition and public health as a 9 to 5 job. Instead, he was driven by a passion to contribute to our community. Josef Schmidhuber who worked closely with him at FAO said, "Prakash was exceptional in every regard; as a colleague, a researcher and a friend". Perhaps Alan Jackson, a good friend and colleague over 40 years, said it best when he wrote on Prakash's passing, 'There are some lives that have a remarkable quality and luminosity that touches, helps and enriches the world for others'. May his soul rest in peace.

Epilogue: The authors knew Prakash Shetty very well at different stages of his remarkable career. We have put together our recollections of this humble man who inspired so many in India and abroad. We extend our deepest condolences to his wife, Nandini, children Dushyant and Meghna and their spouses and children. We hope this memoir serves to celebrate his achievements as a person and scientist, and his family's contribution to his success. We are indebted to many who assisted us in this endeavour and apologise to those we could not contact in time. In particular, we wish to thank Abraham Joseph, P Zachariah, Shiv Pillai, Josef Schmidhuber and Alan A Jackson.

\section{Compliance with ethical standards}

Conflict of interest The authors declare that they have no conflict of interest.

\section{References}

1. James WP, Shetty PS. Metabolic adaptation and energy requirements in developing countries. Hum Nutr Clin Nutr. 1982;36:331-6.

2. Jung RT, Shetty PS, James WP, Barrand MA, Callingham BA. Reduced thermogenesis in obesity. Nature. 1979;279:322-3.

3. Jung RT, Shetty PS, James WP, Barrand MA, Callingham BA. Effect of catecholamine replacement with levodopa on the metabolic response to semistarvation. Lancet. 1979;8107:77-9.

4. Shetty PS. Adaptations to low energy intakes: the responses and limits to low energy intake in infants, children and adults. Eur J Clin Nutr. 1999;53((Suppl.1):S14-33.

5. Durnin JV, Garlick P, Jackson AA, Schürh B, Shetty PS, Waterlow JC. Report of the IDECG Working Group on lower limits of energy and protein and upper limits of protein intakes. International Dietary Energy Consultative Group. Eur J Clin Nutr. 1999;53(Suppl 1):S174-6.

6. Muralidhara DV, Shetty PS. A closed circuit apparatus for measurement of oxygen consumption in small animals. Indian $\mathrm{J}$ Physiol Pharmacol. 1983;27:345-9.

7. Shetty PS, Sheela ML, Murgatroyd PR, Kurpad AV. An opencircuit indirect whole body calorimeter for the continuous measurement of energy expenditure of man in the tropics. Indian $\mathbf{J}$ Med Res. 1987;85:453-60.

8. Shetty PS, James WP. Body mass index. A measure of chronic energy deficiency in adults. FAO Food Nutr Pap. 1994;56:1-57. 
9. Soares MJ, Piers LS, Shetty PS, Jackson AA, Waterlow JC. Whole body protein turnover in chronically undernourished individuals. Clin Sci. 1994;86:441-6.

10. Shetty PS. A critical analysis of Avicenna's contribution to physiology. Bull Indian Inst Hist Med Hyderabad. 1981;1-4:152-60.

11. Schmidhuber J, Shetty P. The nutrition transition to 2030; Why developing countries are likely to bear the major burden. Acta Agric Scand. 2005;2:150-66.
12. Shetty P, Schmidhuber J. The epidemiology and determinants of obesity in developed and developing Countries. Int J Vitam Nutr Res. 2006;76:157-62.

13. Seidell J, Shetty P. Editorial. The baton passes on. Eur J Clin Nutr. 2007;61:1-2.

14. Shetty P. Nutrition sensitive agriculture to achieve better nutritional outcomes. Eur J Clin Nutr. 2018;72:1296-9. 